\title{
Comparative Study on Mechanical Properties of Bamboo Strip and Bamboo Strip- Glass Fiber Reinforced Hybrid Composites
}

\author{
Mahir Asif, Kazi Adnan Rahman, Mohammad Omar Faisal and Md. Shariful Islam* \\ Department of Mechanical Engineering, Khulna University of Engineering \& Technology, Khulna-9203, BANGLADESH
}

Received: March 23, 2020, Revised: April 01, 2020, Accepted: April 01, 2020, Available Online: April 02, 2020

\begin{abstract}
In this paper, mechanical properties of bamboo strip and bamboo strip-glass fiber reinforced hybrid composite were investigated. Composites were manufactured by using hand lay-up technique and bamboo strips were made from locally available bamboo. Four layers of bamboo strip composite were manufactured and in case of hybrid composite, two layers of glass fiber one at the top and the other at the bottom were used with the aim was to observe the effect of adding glass fiber layer on the mechanical properties of bamboo strip composite. Tensile and flexural properties were studied and it was found that adding the glass fiber layer doesn't have any significant effect on tensile properties but flexural strength and modulus have increased by $22.49 \%$ and $15.02 \%$ respectively.
\end{abstract}

Keywords: Bamboo Strip; Hybrid Composite; Tensile Strength; Flexural Strength.

This work is licensed under a Creative Commons Attribution-NonCommercial 4.0 International

\section{Introduction}

Fiber-reinforced plastic (FRP) is a thermoset polymer composite material which is made of a polymer matrix reinforced with fibers. Based on the source, fibers are divided mainly into two categories: natural and synthetic. The natural fibers such as cellulose fiber, wood fiber, flax, hemp, silk, jute, sisal, kenaf, cotton, and synthetic fibers such as glass, carbon, or aramid so on are being used to reinforce thermoplastics and thermosets by many researchers. Epoxy, vinyl ester, or polyester thermosetting plastic are used as the polymer matrix. Fiber-reinforced polymer composites are commonly used in the aerospace, automotive, marine, and construction industries [1]. The usage of FRP composites continues to grow at a staggering rate, and they are introduced in fields such as biomedical devices and civil structures [2]. This boom is due to the development of new advanced forms of FRP materials, which include highperformance resin systems and developed styles of reinforcement [2]. Properties such as lightweight, no-corrosive, exhibit high specific strength and specific stiffness, simple manufacturing process are the reasons FRP is becoming popular day by day.

Natural fibers have many favorable mechanical properties such as low abrasion resistance, low density, high toughness, acceptable specific strength properties, excellent thermal properties, enhanced energy recovery, biodegradability [3], acceptability, and so on [4]. Because of their ecofriendly nature and sustainability, natural fibers are getting attention from researchers and academicians to utilize in polymer composites. Various chemical treatments have been used successfully in enhancing the mechanical properties of natural fibers to overcome noticeable drawbacks in fiber nature [5]. On the other hand, synthetic fibers have been used in research and commercial purposes [6]. High-performance synthetic composites are used to reduce weight in automotive, aerospace, and other transport applications. Thus, savings in running costs are ensured, and more significantly, carbon emission is reduced, helping to increase resource efficiency and drive our shift to low carbon vehicles.

Bamboo is an abundant natural resource found in Asia, which is used for structural purposes, e.g., building houses, making temporary bridges in rural areas from ages [7]. It has the fastest growth rates amongst the natural fibers. It grows to its fullest within 6-8 months [8]. Besides, bamboo fibers contain $60 \%$ cellulose, a considerably high percentage $(32 \%)$ of lignin [9]. These lignocellulosic fibers are capable of imparting high strength in materials. Also, bamboo fiber-reinforced composites have low density, high specific strength, fewer health hazards, less machine wear during processing. Most significantly, the costs of bamboo species are very low per unit volume, and consequently, the production cost can be reduced to a great extent. So, bamboo can be used as a reinforcing agent in composite material. Among the synthetic fibers, glass fibers based on silica $\left(\mathrm{SiO}_{2}\right)$ with additions of oxides of calcium, boron, iron, and aluminum - are the most common reinforcement used in various applications to replace more substantial metal parts. Although these fibers weigh more than carbon, their impactresistant properties are better than carbon fiber. Depending upon the glass type, filament diameter, sizing chemistry and fiber form, a wide variety of features and performance levels can be obtained [10], but it is the different concentrations of metal oxides that allow different glass types to be produced.

Recent researches have been focused on the mechanical properties of natural fibers like jute, wood, coir, and bamboo. Lakkad et al. [11] and Jindal [11] reported on the mechanical properties of bamboo, and Pakotiprapha et al. [13] reported on the reinforcement of cement by bamboo fibers. Rajulu et al. [14] investigated the effect of fiber length on the tensile properties of short bamboo fiber epoxy composite. Chen et al. [8] investigated the mechanical properties of bamboo fiber-reinforced polypropylene and compared the results with those of commercial wood-pulp. Thwe et al. [15] investigated the effect of actual environmental aging on the mechanical properties of bamboo-glass fiber reinforced polymer hybrid composites. 
This paper investigates the mechanical properties of bamboo strip composites and bamboo strip-glass fiber reinforced hybrid composites. The primary focus of this paper was to observe the effect of glass fiber layer on the mechanical properties of hybrid composites.

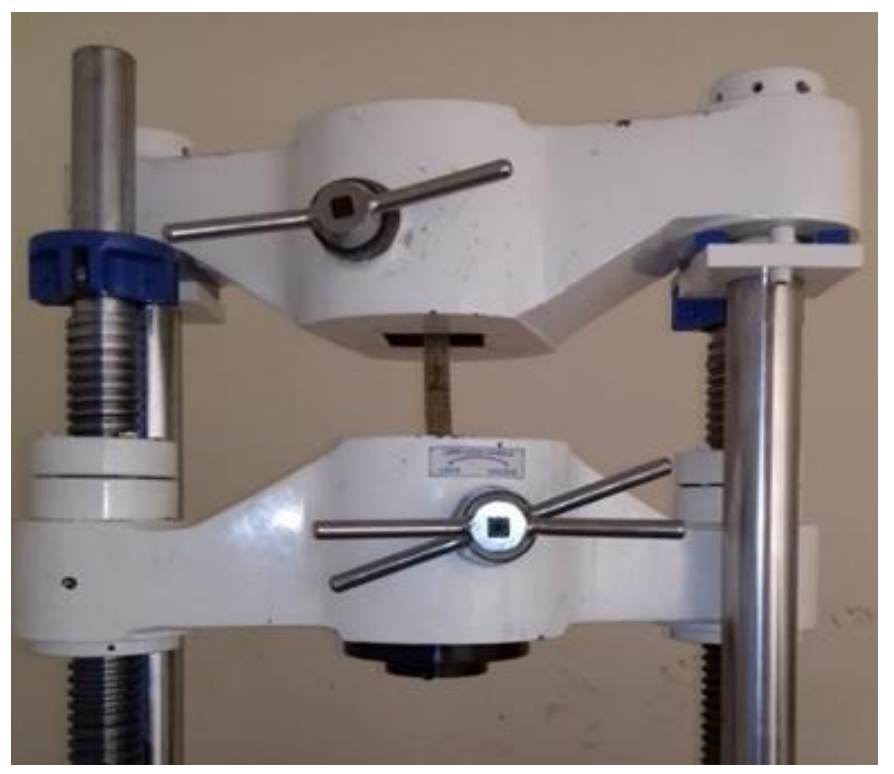

Fig. 1 Experimental setup for tensile test

\section{Experimental Details}

\subsection{Materials}

Bamboo strip and glass fiber was used as reinforcing material. The bamboo species used for the preparation of composites was Bambusa Paravariabilis, which grows abundantly in this part of Asia. Bamboo chips were cut using a wood planer, which were then ground into long strips manually by knives, and were then dried in sunlight for 3 days afterward. Otherwise, for hydrophilic behavior, bamboo strips would absorb moisture, which might affect the quality of the composite. Then the pieces were woven in a plain weave pattern to a $300 \times 300 \mathrm{~mm}^{2}$ square shape.

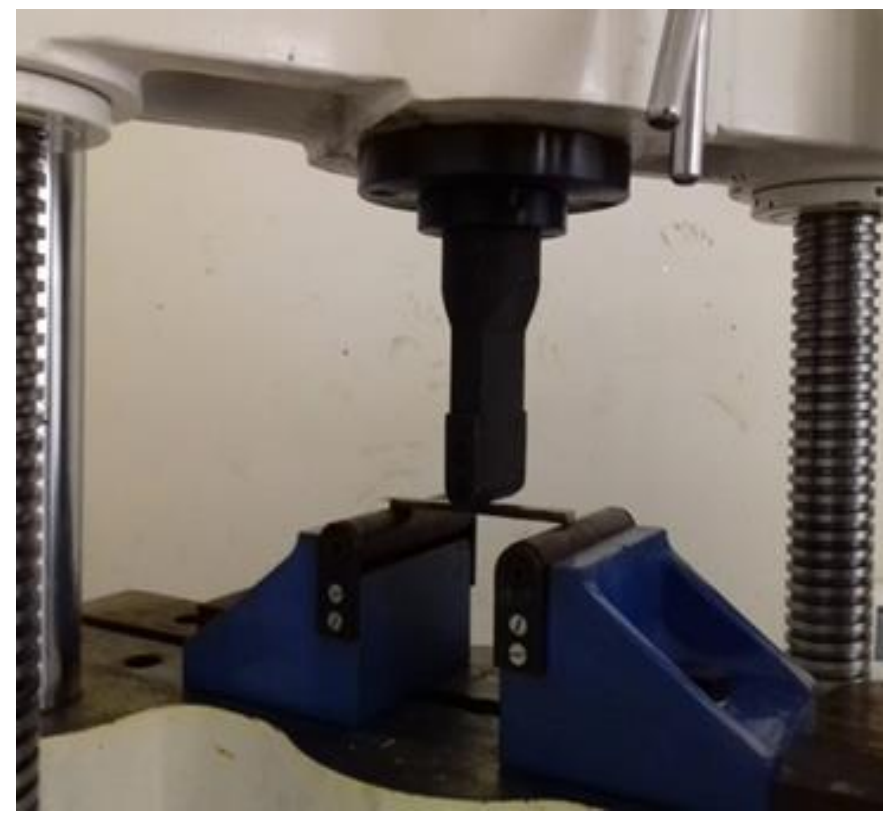

Fig. 2 Experimental setup for flexural test
On the other hand, non- woven, stitch-bonded cloth type glass fiber with a thickness of $0.03 \mathrm{~mm}$ was used. For the composite fabrication, epoxy resin and hardener were used. The hardener was mixed with the adhesive at a ratio of 1:10 as recommended by the manufacturer. This resin was chosen because of its accessibility and compatibility with natural fibers.

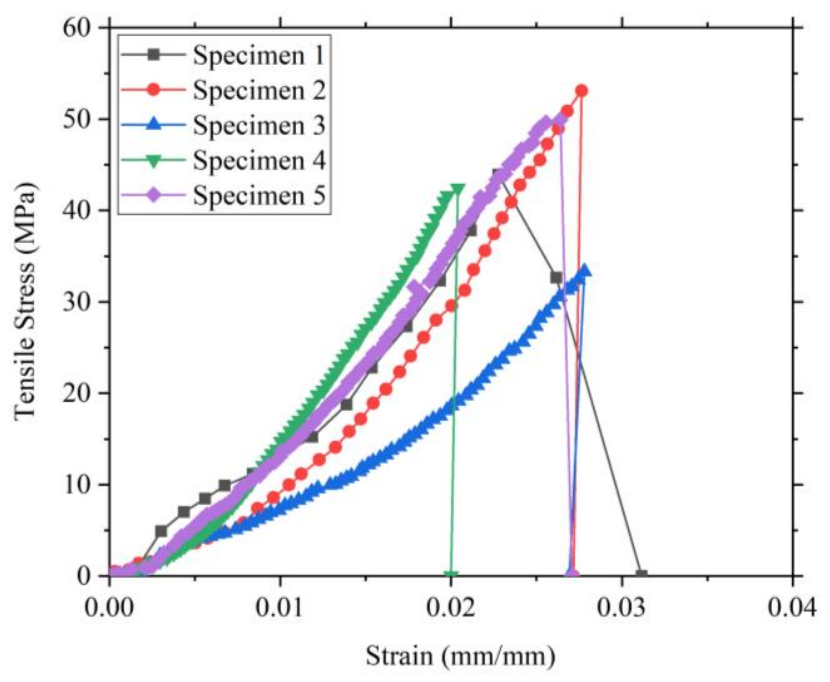

(a)

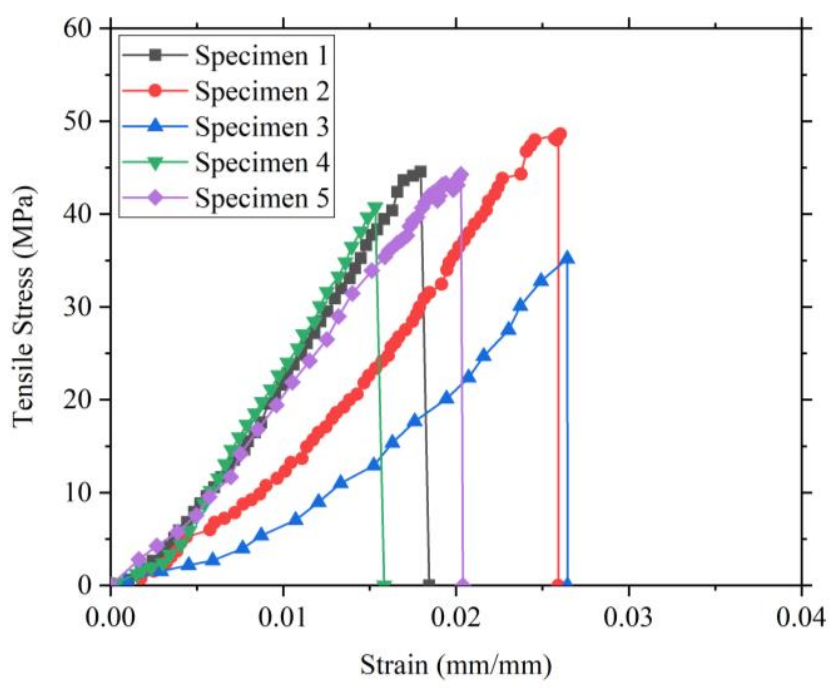

(b)

Fig. 3 Stress-strain diagram for the tensile test of (a) bamboo strip and (b) hybrid composite

\subsection{Manufacturing Process}

Manufacturing of the composite was done using the hand lay-up process. At first, the laminated composites with a total of four plies were manufactured with epoxy resin by hand layup technique. Rectangular stainless-steel plate with a size of $300 \mathrm{~mm} \times 300 \mathrm{~mm}$ was taken as a mold plate. Two stainless steel mold plate were used at the top and bottom of composite laminate during manufacturing of composites. At first, the bottom mold plate were positioned and on the top surface of that mold plate lubricating oil was brushed which acts as a mold release. The first layer of fiber was placed on top of the bottom mold plate. Resin was the poured on the first layer and the resin was uniformly distributed with the help of brush and roller. The 
second layer of the fiber was placed on top of the first layer and similar procedure repeated for all the successive layer. Once all the fiber layer were placed and resin was poured and distributed evenly, top mold plate was then placed on top of the top fiber layer. Again, the bottom surface of the top mold plate was lubricated for the easy removal of composite after curing. A pressure of $1 \mathrm{MPa}$ was applied evenly on the top mold plate and leave it for 24 hours for curing at room temperature. After curing, the composite laminate was removed and cut into pieces for tensile and flexural testing following the corresponding ASTM standard. Note that, for the manufacturing of bamboo composite, 4 layers of woven bamboo strips were used and for the hybrid composite, along with 4 layers of bamboo, 2 layers of glass fiber were placed on the top and bottom surfaces.

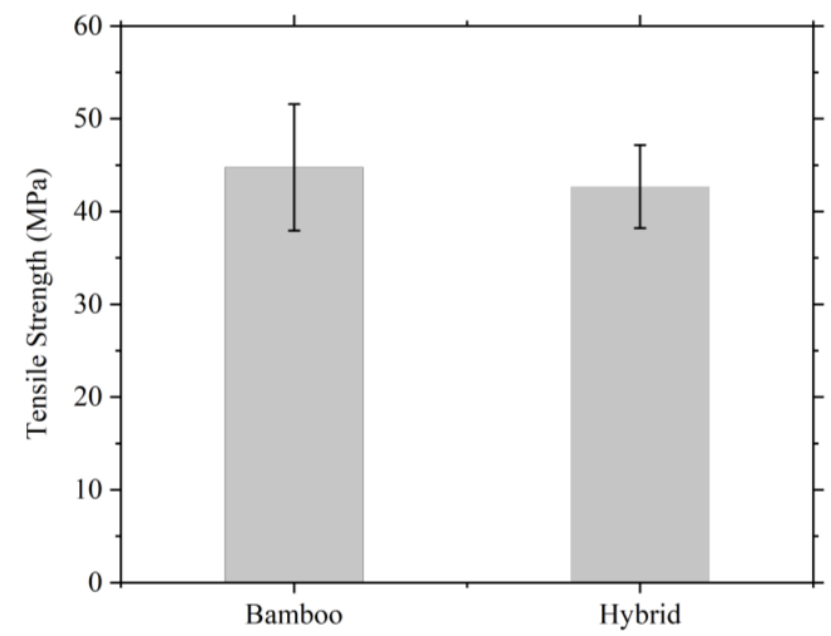

(a)

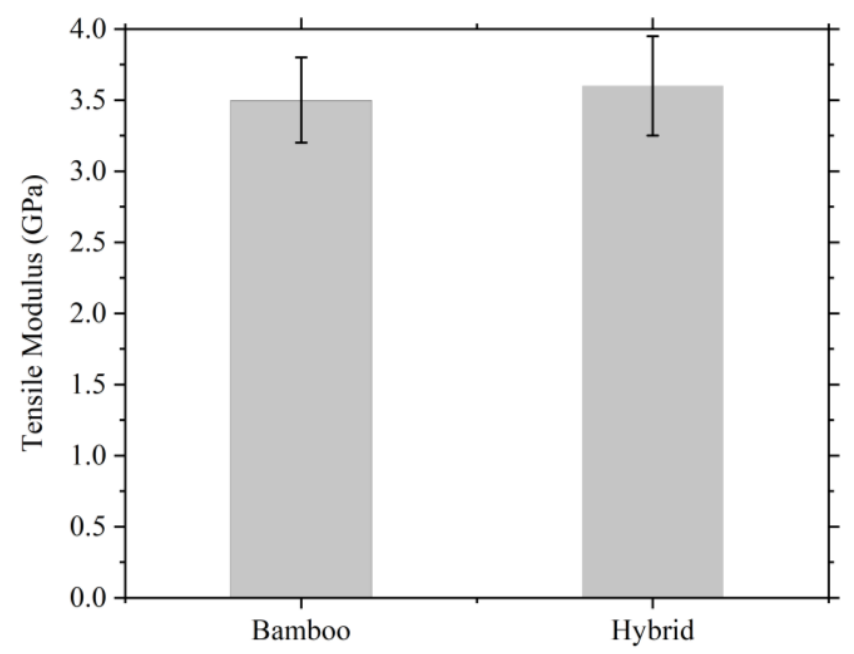

(b)

Fig. 4 Comparison of tensile properties of bamboo and hybrid composite (a) strength and (b) modulus

\subsection{Tensile Test}

Tensile tests in longitudinal directions of the manufactured bamboo strip composite and hybrid composite were conducted as per the ASTM D3039 standard [16]. Tensile test specimens were cut parallel to the fiber direction with the following dimensions: length $250 \mathrm{~mm}$, width $25 \mathrm{~mm}$. For each composite type, five identical samples were tested. The tensile test was conducted using a $2 \mathrm{~mm} / \mathrm{min}$ crosshead speed. Fig. 1 shows the tensile test setup at the universal testing machine.

\subsection{Flexural Test}

Flexural tests were conducted on a three-point bending machine (refer to Fig. 2) following the ASTM D7264 standard [17]. Specimens of $125 \mathrm{~mm}$ length and $13 \mathrm{~mm}$ width were cut and were loaded in a three-point bending test with a recommended span-to-thickness ratio of 16:1. The specimen length was about $20 \%$ longer than the support span. Five identical specimens were tested for each composite.

\section{Results and Discussion}

\subsection{Tensile Test Results}

Tensile tests were performed on five bamboo fiber reinforced composites and five bamboo-glass fiber reinforced hybrid composites. Fig. 3 shows the stress strain diagram for the tensile test. It is observed from Fig. 3 (a) that the maximum tensile stress for bamboo fiber composite varies from sample to sample while the maximum tensile stress for hybrid composites are more consistent.

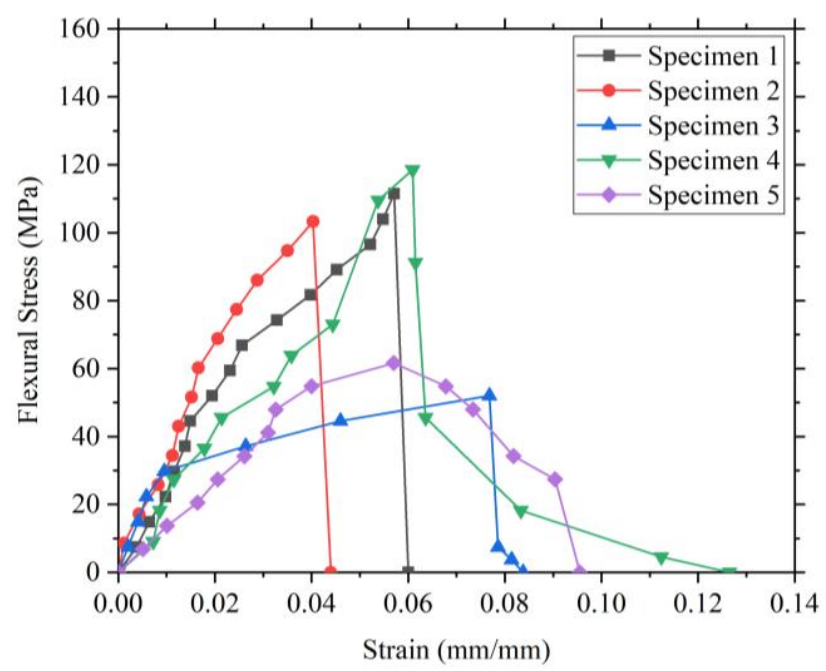

(a)

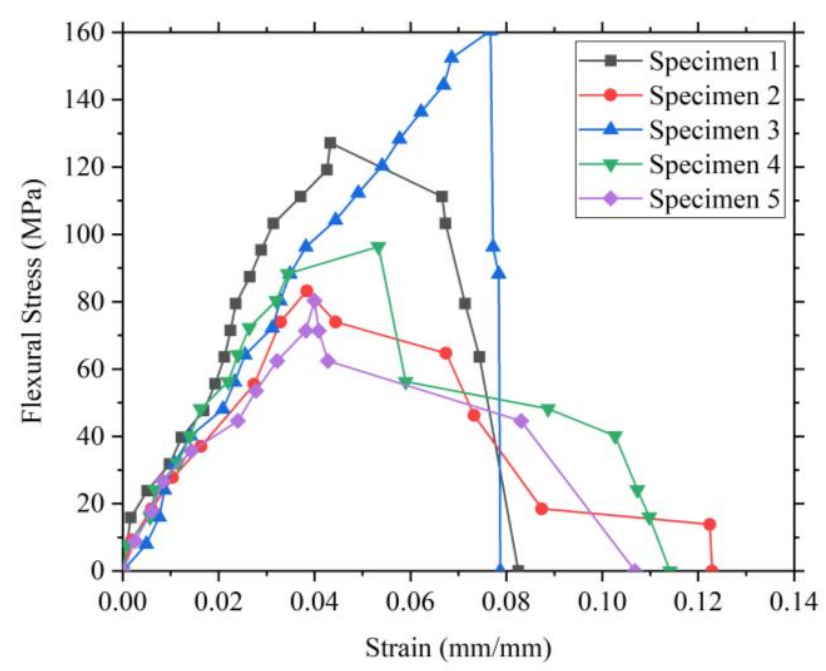

(b)

Fig. 5 Stress-strain diagram for the flexural test of (a) bamboo strip and (b) hybrid composite 
Fig. 4 shows the comparison of tensile strength and modulus of bamboo fiber and hybrid composite. It can be observed from this figure, that both the tensile strength and modulus remains almost constant for both composites which indicates that, adding glass fiber layers doesn't have significant effect on the tensile properties.

\subsection{Flexural Test Results}

Flexural tests were also performed on five bamboo strip and five hybrid composite specimen. Fig. 5 shows stress strain diagram for both bamboo strip and hybrid composite. It is observed from this figure, that the maximum stresses in Fig. 5 (b) compared to Fig. 5 (a) are higher which indicates that flexural strength for hybrid composite is higher compared to bamboo fiber reinforced composite. This can also be seen in Fig. 6 (a) which shows the flexural strength for hybrid composite is $22.49 \%$ greater than bamboo fiber composite. It is also observed from Fig. 5 (b) that slope of the lines are stiffer than in Fig. 5 (a) which implies a greater flexural modulus for hybrid composite compared to bamboo fiber composite. Fig. 6 (b) confirms this statement which shows a $15.02 \%$ increase in flexural modulus in case of hybrid composite.

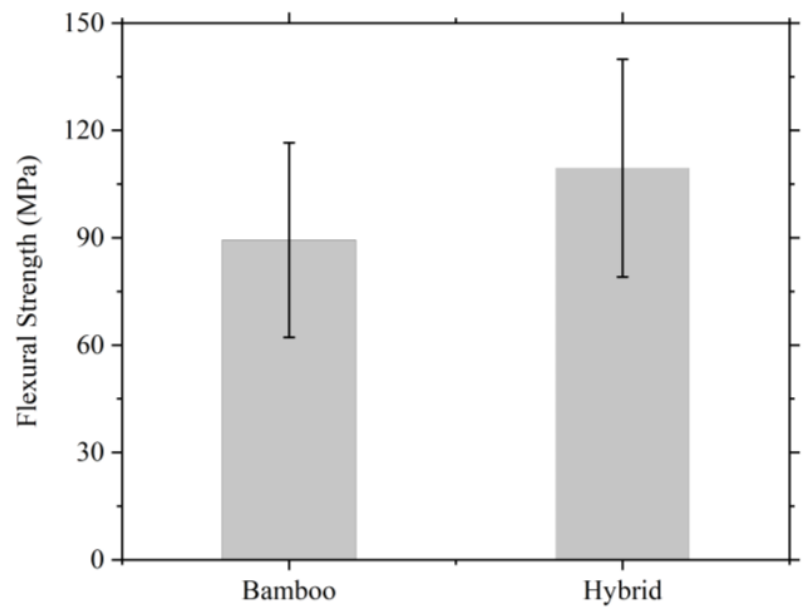

(a)

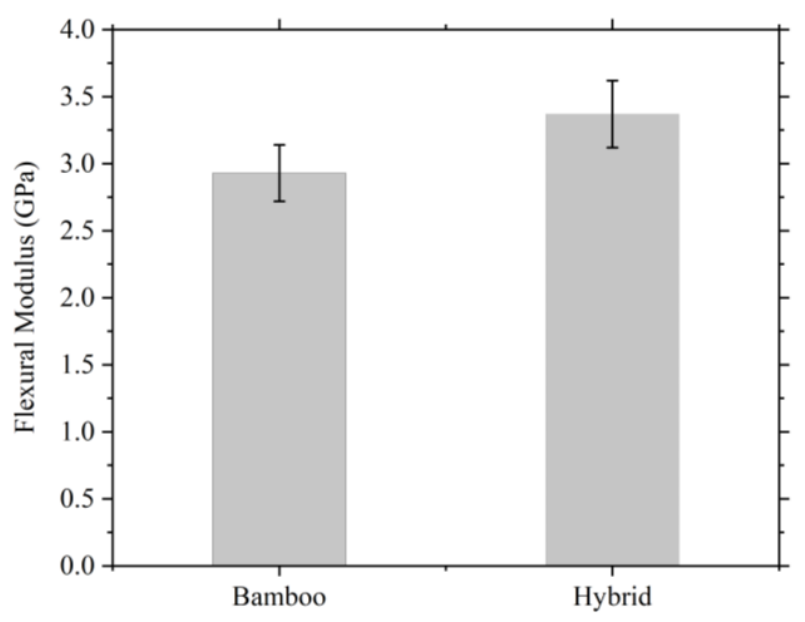

(b)

Fig. 6 Comparison of flexural properties of bamboo and hybrid composite (a) strength and (b) modulus

\section{Conclusion}

The comparative analysis of tensile and flexural properties of the bamboo fiber and bamboo-glass fiber composite was done. The results concluded that in the case of tensile properties, there is no significant change in the tensile strength and modulus. On the other hand, a $22.49 \%$ increase in flexural strength and $15.02 \%$ increase in flexural modulus was observed for hybrid composites. Since no significant effect in the tensile properties observed, the bamboo strip composite can be used where tensile strength is of primary concern i.e., the structural application like tension member in frames, whereas the hybrid composite can be used in bridges, column support where flexural strength is of greater interest.

\section{Acknowledgement}

The authors would like to acknowledge the financial sponsorship from the UGC funded project at Khulna University of Engineering \& Technology to conduct the research.

\section{References}

[1] Jose JP, Thomas S, Kuruvilla J, Malhotra SK, Goda K, Sreekala MS. Advances in polymer composites: macroand microcomposites - state of the art, new challenges, and opportunities. Polymer Composite: Macro-and Microcomposites. Weinheim: Wiley-VCH Verlag $\mathrm{GmbH}$ Co. KGaA. 2012;1:3-4.

[2] Tong L, Mouritz AP, Bannister MK. 3D fibre reinforced polymer composites. Elsevier; 2002 Nov 20.

[3] Herrera-Franco P, Valadez-Gonzalez A. A study of the mechanical properties of short natural-fiber reinforced composites. Composites Part B: Engineering. 2005 Dec 1;36(8):597-608.

[4] Shubhra QT, Alam AK, Quaiyyum MA. Mechanical properties of polypropylene composites: A review. Journal of thermoplastic composite materials. 2013 Apr;26(3):362-91.

[5] Liu D, McDaid AJ, Aw KC, Xie SQ. Position control of an ionic polymer metal composite actuated rotary joint using iterative feedback tuning. Mechatronics. 2011 Feb $1 ; 21(1): 315-28$.

[6] Geethamma VG, Mathew KT, Lakshminarayanan R, Thomas S. Composite of short coir fibres and natural rubber: effect of chemical modification, loading and orientation of fibre. Polymer. 1998 Jan 1;39(6-7):1483-91.

[7] Shin FG, Xian XJ, Zheng WP, Yipp MW. Analyses of the mechanical properties and microstructure of bambooepoxy composites. Journal of Materials Science. 1989 Oct 1;24(10):3483-90.

[8] Chen X, Guo Q, Mi Y. Bamboo fiber-reinforced polypropylene composites: A study of the mechanical properties. Journal of applied polymer science. 1998 Sep 6;69(10):1891-9.

[9] Chattopadhyay SK, Khandal RK, Uppaluri R, Ghoshal AK. Bamboo fiber reinforced polypropylene composites and their mechanical, thermal, and morphological properties. Journal of applied polymer science. $2011 \mathrm{Feb}$ 5;119(3):1619-26. 
[10] Lawton EL, Wallenberger FT, Li H. Recent Advances in Oxide Glass Fiber Science. MRS Online Proceedings Library Archive. 2001;702.

[12]Jindal UC. Development and testing of bamboo-fibres reinforced plastic composites. Journal of Composite Materials. 1986 Jan;20(1):19-29.

[13] Pakotiprapha B, Pama RP, Lee SL. A study of bamboo pulp and fiber cement composites. InSymposium on Reduction of Housing Costs, Topic III 1978 (Vol. 220).

[14] Rajulu AV, Baksh SA, Reddy GR, Chary KN. Chemical resistance and tensile properties of short bamboo fiber reinforced epoxy composites. Journal of reinforced plastics and composites. 1998 Dec;17(17):1507-11.
[11]Lakkad SC, Patel JM. Mechanical properties of bamboo, a natural composite. Fibre science and technology. 1981 Jun 1;14(4):319-22.

[15] Thwe MM, Liao K. Effects of environmental aging on the mechanical properties of bamboo-glass fiber reinforced polymer matrix hybrid composites. Composites Part A: Applied Science and Manufacturing. 2002 Jan 1;33(1):4352.

[16] ASTM D. 3039. Standard test method for tensile properties of polymer matrix composite materials. Annual book of ASTM standards. 2000;15:106-8.

[17]ASTM D7264.. Standard test method for flexural properties of polymer matrix composite materials. American Society for Testing and Materials Annual Book of ASTM Standards. 2007. 